\title{
COMENTARIO A "EN CONTRA DEL POPULISMO REACCIONARIO: HACIA UNA NUEVA ARQUEOLOGÍA PÚBLICA", DE ALFREDO GONZÁLEZ RUIBAL, PABLO ALONSO GONZÁLEZ Y FELIPE CRIADO-BOADO*
}

\author{
Alejandro Haber ${ }^{1}$
}

González-Ruibal, Alonso González y CriadoBoado realizan un conjunto de críticas a las recientes orientaciones multiculturalistas de los estudios de patrimonio en boga en la academia angloparlante. No se puede estar en desacuerdo con muchas de esas críticas, la mayoría de las cuales giran en derredor de la ingenuidad política y la superficialidad teórica imperantes en los estudios sobre patrimonio. La falta de problematización teórica y metodológica de la arqueología de comunidad y de los estudios críticos del patrimonio son, tal vez, una de sus falencias más notables. No hace falta revisitar estos puntos, por cuanto los autores han hecho de ellos la parte sustancial del manifiesto que aquí comento. Me concentraré, en cambio, en mostrar que la propositiva que postulan como sendero alternativo tiene un sentido declarativo, pero avanza muy poco en superar los problemas que detectan en el blanco de sus críticas.

Una de las principales críticas, que los autores resumen como "populismo reaccionario", alude a una lectura simplificada, homogeneizadora y optimista respecto de "la comunidad" o "el pueblo", es decir, los destinatarios del trabajo arqueológico. Es evidente que las localidades no son simples, están compuestas de sectores y grupos, fundamentalmente de intereses diferentes, privilegios diversos y violencias estratificadas. Se trata del mundo colonial, pues, no de una novela romántica (y cuando se dice 'mundo colonial' ello no se circunscribe a la geografía actual o pretérita de colonias políticas). Las localidades tampoco son homogéneas, pues están integradas por disímiles participantes: no humanos, ausencias, dioses, incluso sitios arqueológicos, también humanos. Orientar la intervención patrimonial hacia la comunidad o el pueblo como un todo suele enfrentarse con la circunstancia de que los beneficiarios del patrimonio no merecen nuestra solidaridad, o bien sí la merecen pero no desean la oferta arqueológica de pasado y patrimonio. Sobre esto se pueden decir al menos dos cosas. Una: las localidades no solo son complejas y heterogéneas, sino que están tensadas por antagonismos. Podemos componer intereses con algunos, lo cual implicará antagonizar con otros. Si, en cambio, elegimosnocomprometernos conintereses locales, nuestra intervención se comprometerá con una intervención colonial. Dos: el patrimonio y el pasado son posiciones establecidas en el marco de una política de conocimiento. Las localidades tienen sus propias posiciones epistémicas, la arqueología disciplinaria otras. Ambas se encuentran enredadas en antagonismos epistémicos. Con todo esto, que podría desarrollarse muchísimo más, resulta evidente que una lectura simplificada, homogénea y optimista de las localidades resulta ingenua e insuficiente. Pero nada de ello significa que debamos descartar a las localidades como eje de la intervención patrimonial, lo que parece ser la propuesta de los autores. En todo caso, se trata de dotarnos de metodologías que nos permitan componer intereses en situaciones locales complejas, heterogéneas, fluidas, contestadas, compuestas por antagonismos, en las que nuestras certezas epistémicas y solidaridades constitutivas resulten movilizadas. Incluso más problemática resulta la apuesta de los autores por una pedagógica de la experticia. Esta no solo pasa por alto la política de conocimiento en la que se establece la experticia, sino que, desde esa posición, que cabe caracterizar al menos como acrítica, se propone 'enseñarla' al conjunto social. Decir sin más que "necesitamos una arqueología implicada en las explicaciones históricas" supone que las explicaciones históricas, la historia, el pasado, son cosas incontestadas que se alojan en una sola versión aceptable, y desconoce que las explicaciones históricas son ellas mismas productoras de colonialidad.

Los autores ven la necesidad de desvincularse de comunidades específicas y desarrollar una práctica pedagógica hacia los públicos (o hacia el pueblo) incluso independiente. ¿Acaso no es precisamente eso lo que la ciencia moderna, en su más acrítica versión,

\footnotetext{
* Nota de la editora: Chungara Revista de Antropología Chilena presenta los comentarios críticos realizados por ocho arqueólogos latinoamericanos al estimulante y provocativo artículo recientemente publicado en inglés "Against reactionary populism: toward a new public archaeology" en la revista Antiquity 2018, 92 (362):507-515, de los autores Alfredo González-Ruibal, Pablo Alonso González y Felipe Criado-Boado, cuya versión en español se encuentra disponible en www.chungara.cl. Los destacados arqueólogos Manuel Gándara Vázquez (México), Wilhelm Londoño (Colombia), Pedro Paulo A. Funari y Andrés Alarcón-Jiménez (Brasil), Henry Tantaleán (Perú), Alejandro Haber (Argentina), Félix Acuto (Argentina), y Dante Angelo (Chile), contribuyen sustancialmente al debate, desde sus visiones críticas de cómo el patrimonio y la arqueología pública es entendida y practicada en nuestros países latinoamericanos.

${ }^{1}$ Profesor Titular de la Universidad Nacional de Catamarca e Investigador Principal del Consejo Nacional de Investigaciones Científicas y Técnicas Argentina. afhaber@gmail.com
} 
pretendía y pretende? Resulta al menos curioso, pero se podría adjetivar más, que los autores ejemplifiquen con las obras de Childe y Renfrew la supuesta independencia situacional de los discursos académicos. Como se suele decir, los autores han decidido descartar al bebé junto con el agua de baño, y terminan por adoptar posiciones más reaccionarias aún que aquellas que condenan por reaccionarias. ¿Acaso debemos volver a creer en la neutralidad valorativa e independencia de intereses sociales de los discursos y prácticas académicas?

Tanto abrazar (lo que en la perspectiva de los autores harían los Estudios Críticos del Patrimonio) como rechazar (lo que hacen los autores) a las comunidades como si fuesen un todo homogéneo supone una fatal ingenuidad. Las situaciones siempre son contestadas y atravesadas por antagonismos, de los cuales también los académicos inevitablemente formamos parte. Solo reconociendo el lugar de nuestra práctica y pensamiento en los antagonismos es posible componer intereses con las comunidades de conversación, que no significa que será con la totalidad del 'pueblo', ni con la 'comunidad' homogénea, sino con quienes componemos intereses de acuerdo con los antagonismos que conforman la situación. Establecer el sentido de la práctica respecto del patrimonio en el beneficio de la comunidad como un homogéneo no deja de ser una justificación altruista de una intervención colonial. Pero refugiarse en un pretendido lugar no situado no es sino una coartada autoritaria que busca elaborar un lugar neutro desprovisto de intereses. Lo que necesitamos, en mi modo de ver y a diferencia de lo que proponen los autores, es localizar y situar todos los discursos, empezando por los nuestros; conocemos las consecuencias desastrosas de las intervenciones no egoístas en beneficio del otro, también conocemos la ficción del no-lugar de la ciencia, sus intereses y sus consecuencias. Sería materia de otro texto desmitificar en qué sentidos podría lo primero pasar por crítico y lo segundo por progresista.

El movimiento de abandono de la situacionalidad, que los autores pretenden justificar en discusión con la visión -que declaran acrítica- de los estudios críticos del patrimonio, no es sino volverse más acrítico aún, sobre todo respecto de los propios intereses sociales. Ello se torna patente en el lamento que los autores reiteran frente a la "crisis" de la industria de la arqueología de contrato. $\mathrm{Si}$ bien es cierto que, como escriben los autores, se trata de una crisis promovida por el objetivo de maximizar la renta capitalista de las intervenciones territoriales, los autores permanecen ciegos -y mudos- a la crítica teórica que en América del Sur se viene debatiendo respecto de las implicancias éticas, políticas y epistémicas de la arqueología de contrato (Gnecco y Schmidt Dias 2017). El de los autores no es una crítica que discuta, recoja -o se conmueva con- ese debate, sino más bien un lamento corporativo que defiende los intereses del sector de la industria.
El proceso de maximización neoliberal de la renta capitalista, una de cuyas víctimas -y no la más trágicaparece ser el esquema de gestión de las intervenciones territoriales conocido como impacto y que ha dado lugar a una de las reconversiones posdisciplinarias más populares de la arqueología, merece más, y no menos, trabajo teórico; más crítica de los supuestos disciplinarios y no más experticia y blindaje de la disciplina. Es decir, que en algunos países las condiciones socioburocráticas hayan modificado y reducido el mercado de la arqueología de contrato, no debe llevar a detener el trabajo de crítica teórica-metodológica y a refugiarse en posiciones acríticas y autoritarias que giran en torno a la experticia disciplinaria. Si esto se acometiera desde una trinchera sectorial corporativa, malamente podría llamárselo 'independencia' respecto de una comunidad específica, pues resulta bastante visible que se trata de un pensamiento socialmente interesado. Si, además, desde ese lugar de pretendida neutralidad se emprende una tarea pedagógica, todo cuanto parece esconder una tal "nueva arqueología pública" podría resumirse como un nuevo proyecto de codificación académica de la colonialidad.

Para terminar, debo referirme a la situación discursiva editorial del texto que me toca comentar. A la lectora no se le escapa que el texto y, por lo tanto, este comentario, están fuera de lugar. Los autores, tres colegas españoles de conocida interacción con la arqueología suramericana, han intervenido en el debate acerca del patrimonio como si la manera en la que este se presenta en Europa fuese universal. El texto, escrito para su publicación en Antiquity, abunda en categorías políticas y teóricas de uso en Europa y cuyo significado en Suramérica es bien distinto, hasta opuesto. Eso no tendría mayor interés, si no alcanzara a advertir que, reiterando el canon geopolítico occidental moderno, las desmarcaciones situacionales y contextuales configuran el texto como escrito en lenguaje universal. Como si no bastara, han omitido la producción crítica sobre el patrimonio y la práctica arqueológica que, en América del Sur y de manera independiente y original, ha dado estos debates y ha provocado discusiones, incluso eludiendo la fuga reaccionaria que los autores defienden como superación del populismo reaccionario. Su publicación en Chungara, un conocido periódico suramericano, y esta rueda de comentarios en la que escribo, están, por consiguiente, deslocalizados. Esta circunstancia, no obstante, no es sorprendente, sino todo lo contrario: presentar sin marcas situacionales, es decir, como universal, el pensamiento localizado en la metrópoli es un tropo que conocemos bien, aunque pocas veces nos demoramos en pensar sus consecuencias. Tiene el efecto, entre otros, de trasladar la localización de nuestro propio pensamiento a la periferia. Si bien los autores podrían argumentar que la academia española resulta periférica en el contexto europeo, sobre todo respecto de 
la academia angloparlante hacia la que parecen reservar su mirada crítica, la elusión del debate en América del Sur y su posterior inclusión en este órgano para que sea debatido aquí, lleva el signo del pensamiento colonial. La reversa -la presentación en Europa de un debate suramericano- solo sería admisible bajo la marca de la teoría de área, ya no desmarcada o universal. Por ejemplo, se reconocen en el texto tres cuerpos de pensamiento, los "estudios críticos del patrimonio" -autores mayoritariamente angloescandinavos, blanco de la crítica de los autores, sin situación geográfica-; los "autores" -españoles masculinos que critican, sin situación geográfica y con marcación en género femenino-; y los "sudamericanos", de los que mucho no se habla y quienes tampoco hablan, pero portan la marca de su situación geográfica como fundamental y esencial característica. Esta cuestión lleva directamente a uno de los supuestos fuertes del texto, al que ya me referí: la pretensión del pensamiento -y la escritura del pensamiento- no situado.
Con esto acaba este comentario, no sin insistir en un punto, tal vez el más importante. Estoy en profundo desacuerdo en que haga falta recuperar la independencia respecto de colectivos específicos, reservar un estadio de autoridad académica de los discursos arqueológicos, o emprender una cruzada pedagógica sobre el público. Creo, en cambio, que es necesario desarrollar metodologías situacionales, interculturales, que privilegien la apertura al aprendizaje antes que a la enseñanza. Metodologías que busquen el lado negativo de la superficie del paisaje y del lenguaje del mundo moderno colonial, que se orienten a ampliar la intersubjetividad en lugar de reservar sitios objetivistas de retención de autoridad, y que arriesguen la afectación de los supuestos epistémicos disciplinarios y culturales en lugar de defender los cotos de las disciplinas con sus deslindes epistémicos, sociales y lingüísticos. No se sale del multiculturalismo con la autoridad de la ciencia sino con pensamiento situado, concreto, afectado por solidaridades constitutivas y en trinchera de la descolonialidad.

\section{Referencia Citada}

Gnecco, C. y A. Schmidt Dias (eds.) 2017. Crítica de la Razón Arqueológica. Arqueología de Contrato y Capitalismo. Instituto Colombiano de Antropología e Historia, Bogotá. 
